\title{
Rubber Band Combination is Applied to Defensive Training of Basketball Player
}

\author{
Xinwen Li \\ Department of Sports, \\ Electronic Science and Technology University, \\ Chengdu, 610054, China
}

\begin{abstract}
Defense is one of the most important aspects of the game who will win. This is be gradually accepted by many people. Today we have number of various defense training methods, but using the auxiliary equipment and simulation technologies, and calculating on the basis of individual differences in athletes and establishing the training model, then Athletes and coaches precise guidance for optimal training results. The current study is also rare. According to the principle of action and reaction, to complete the required defensive athlete technical movements, At this time the muscle groups of athlete will be mobilized to participate. After the principle of gradual long-term recovery plans and excessive training, lifting auxiliary equipment, athletes will greatly enhance the technical and tactical ability, particularly in defense technology capabilities. In this study, we used a combination of elastic rubber band reaction principle, the athletes will be remained load in the process of practice. We will analysis the impact on athletes reaction force, confrontation, stamina, willpower, and many other. So we will simulate the high confrontation of game, achieve the effect of combat training really.
\end{abstract}

\section{Keyword: defense training, Basketball Player}

\section{INTRODUCTION}

We use a rubber band combinations on the school basketball team to defend training. Analysis the changes of Athlete's defensive pace, body and willpower, defensive posture, defense and other effects and changes in vision by this, we will Verified that using a rubber band combination is an effective defense training aids.

\section{DISCUSSED PROBLEMS}

Experimental results show that the players have had a positive change in the following areas after a year of practice, based on statistics and on-site technical assessment team sports game:

\section{A. Individual defensive ability}

Players have enhanced the ability of individual defensive, players use footwork and arm movements predictably and reasonable to reach the purpose of the game, actively seize a favorable position, obstruct and destroy the other offensive players attacking intentions and behavior, And actively compete for control of the ball.

\section{B. The defensive pace}

Athletes defensive footwork turned fast, flexible. Basically legs bent, and keep the head at the same height, keep projection of body between your feet. Legs parallel movement, the focus is basically stable, When the body loses balance, Athletes also can seize the favorable defensive position in time. Athletes may timely use the defensive pace and arm movements to interfere and compete for control of the ball. Defender is facing opponents basically, according to the attackers intent and behavior, making the appropriate defensive action at the same time, blocking and damaging the opponent's attack behavior.

\section{PHYSICAL AND TOUGH WILLPOWER}

Athletes dare to do physical contact in the competition, correctly deal with physical contact, and courage to throw out for the defense. When they attack the ball players, they dare close to the opponent, they are not afraid to turn his arm, hit the buttocks, top thighs. Athletes will turn to be fast and ferocious when they grab, hit, steal the ball. When blocking the Athletes who want to breakthrough, they dare to face the opponent, show their body, courage to fight when grab defensive rebounds, they are good to crowd the bit. They Gradually courage to fight, and be good to fight. They can correctly deal with physical contact, and significantly enhance self-confidence.

\section{DEFENSIVE POSTURE}

After a year of training, athletes can let basic legs open knees, average share the weight in the legs, maintain their body balance. When they defense the athletes without the ball, they will pay attention to the ball and people. When the offensive player has the ball, he will stretche out a hand to the ball, move the other hand side, beware opponents to cut, and change their hands with the change in position of the ball.

\section{THE DEFENSE PERSPECTIVE}

In practice we use the ball in front of his body to control his vision of practitioners themselves. With practice, players can basically controll opponents tthrough adjusting their positions, distances, angles.

\section{CHANGE PHYSICAL FITNESS}

After the adoption of this practice, and in combination with other methods of physical exercise, the physical of athletes begin to decline, individual athletes also appear stronger reaction. But after some time, the athletes improved physical fitness, manifested in movement speed, enthusiasm, shooting rate has improved greatly. In particular, the ability of defense has been improved further strengthen. 


\section{FOULS AND CAUSE FOUL BUTT}

7.1 Fouls changed little in the game, but the number that causing foul butt increased significantly.

7.2 Athletes obtained greater progress in the selecting defensive position, rational utilization of physical contact after through this exercise and other practice methods.

\section{CONCLUSION}

Combination of rubber band practice is a relatively simple and practical training aids, this means in many sports are in use. Now it is applied to defense training of basketball players, athletes should be required to go all out to ensure a reasonable and proper defensive action, it simulated combat scenarios of basketball game. So it will have a positive impact on the physical, technical, and the quality of the athletes. Of course, when we actually use it, we will consider individual differences in athletes, reasonable arrangements exercise load, gradually increase the amount, avoid sports injuries, effect the exercise training.

\section{ACKNOWLEDGEMENTS}

The research work was supported by Scholarship of China and The Project- Sponsored by OATF, UESTC.

\section{CORRESPONDING AUTHOR}

Name: Li Xinwen,

Email: 1242264203@qq.com

Mobile phone: 86-13709094558

\section{REFERENCES}

[1] Chinese Basketball Association basketball competition rules validation[S] Guangming Daily Publishing House, 1998-2002.

[2] Yanghua .Birch Modern Basketball Tactics features and functions[J]Wuhan Institute of Physical Education, 1997(3).

[3] Chen ,Jingsheng.Defensive Tactics Research basketball competition of the 26thOlympic Games[J] Chinese Sports Science and Technology, 1997(10)

[4] Teng Chaoyang .American professional basketball offensive and defensive skills and tactics characteristic [J]. Chengdu Institute of Physical Education, 2003 (1)

[5] Lu dongxing,Zhu Lin.Formation of the basketball player's individual defensive awareness and training $[\mathrm{J}]$. Fujian Sports Science and Technology, 